\title{
Spectral Models for Improving Atmospheric Correction Results in Complex Oceanic Waters around India
}

\author{
Palanisamy Shanmugam, Muniyandi Tholkapiyan \\ Department of Ocean Engineering, Indian Institute of Technology Madras, Chennai, India \\ Email: pshanmugam@iitm.ac.in
}

Received February 17, 2013; revised March 20, 2013; accepted March 27, 2013

Copyright (C) 2013 Palanisamy Shanmugam, Muniyandi Tholkapiyan. This is an open access article distributed under the Creative Commons Attribution License, which permits unrestricted use, distribution, and reproduction in any medium, provided the original work is properly cited.

\begin{abstract}
Atmospheric correction over turbid and productive waters continues to be problematic and often results in excessive errors in retrieved water-leaving radiance and bio-geo-physical products. This may be likely due to overestimation of $\mathrm{L}_{\mathrm{a}}$ $+\mathrm{L}_{\mathrm{ra}}$ (atmospheric signal due to aerosol and Rayleigh scattering) in the visible and thus reduction in $\mathrm{L}_{\mathrm{w}}$ which appears as an elevated pigment concentration. Spectral models for reconstructing the atmospherically distorted data are developed and their results are thoroughly validated with in-situ data from a wide range of waters. Good agreement was found between the retrieved products and in-situ data. Our results indicate that the new spectral models have the potential to improve the accuracy of ocean colour retrievals in optically complex waters, and can become an important part of the processing of data from ocean colour sensors (e.g., Ocean colour monitor OCM2) with only two near-infrared bands (i.e., 765 and $865 \mathrm{~nm}$ ).
\end{abstract}

Keywords: Ocean Colour; Spectral Models; MODIS-Aqua; Algal Blooms; Arabian Sea; India

\section{Introduction}

Ocean colour instruments measure the spectrum of sunlight reflected from the ocean-atmosphere system at several visible and near-infrared (NIR) wavebands. The major portion of these signals is from the contribution of scattering by molecules and particles (aerosols) in the atmosphere $(\sim 80 \%-90 \%)$. The process of removing the atmospherically scattered signal in order to retrieve the ocean colour signal (i.e., water-leaving radiance $\mathrm{L}_{\mathrm{w}}$ ) is referred to as atmospheric correction [1]. The current SeaDAS atmospheric correction ("SAC" for brevity) algorithm for producing the global ocean colour products from SeaWiFS and MODIS uses the algorithm of Gordon and Wang [2]. It specifically uses two near infrared (NIR) bands centered at MODIS 748 and $869 \mathrm{~nm}$ (SeaWiFS 765 and $865 \mathrm{~nm}$ ) to determine aerosol type and estimate the atmospheric effects in the visible by extrapolating the aerosol effect from the NIR into visible bands. Though the basic assumption of negligible waterleaving radiance $\left(L_{w}\right)$ in the NIR for deriving aerosol properties was replaced by Stumpf et al. [3] and then updated by Bailey et al. [4], the SAC algorithm still produces low or negatively biased $\mathrm{L}_{\mathrm{w}}$ at short wavelengths in areas with absorbing aerosols or high biomass concen- trations or sediment levels typical of productive coastal regions.

The principal difficulty in these waters is: 1) the adequacy of aerosol models is presently difficult to judge. This holds true for mineral dust aerosols (from deserts) because their absorption can seriously reduce $\mathrm{L}_{\mathrm{a}}+\mathrm{L}_{\mathrm{ra}}$ (atmospheric signal due to aerosol and Rayleigh scattering) in the visible and their vertical distribution profoundly influences the TOA radiance in the visible (especially in the blue) [1,5]. Moreover, the absorption properties are very difficult to determine on the basis of the observations of $\mathrm{L}_{\mathrm{a}}+\mathrm{L}_{\mathrm{ra}}$ in the NIR which means that in-situ measurements in the visible are required for correction. However, in the visible (especially blue) $L_{w}$ can be significant, and cannot be estimated a priori [1]. 2) The errors involved in extrapolating aerosol reflectance to visible bands are considerably higher and this may require a more realistic method [6]. 3) Assumption of negligible water-leaving radiance in the NIR is not valid in optically complex waters, as high sediment loads and phytoplankton will contribute NIR radiance [6-8]. 4) Although modifications to point 3 (i.e., "non-zero $L_{w}$ in the NIR" based on in-water models and spatial homogeneity assumption) $[6,9]$ show noticeable improvements in 
turbid waters, the problems are still encountered in highly bloomed waters and could be attributed to the inadequacy of aerosol models and inadequate/inappropriate in-water models. Thus, an accurate retrieval of ocean colour has become a prolonging issue and requires an alternate and robust solution.

In this study, spectral models are developed to improve the results of atmospheric correction with standard methods and their results are validated with in-situ data sets. Preliminary results are also presented for a case study using MODIS-Aqua data over highly turbid and productive waters in the Arabian Sea.

\section{Data and Methods}

\subsection{In-Situ Data}

In-situ data radiometric data at key wavelengths and pigment (Chlorophyll) concentrations for different regions were obtained from the NASA bio-Optical Marine Algorithm Data set (NOMAD) [10]. These data are global, high quality bio-optical datasets collected over a wide range of optical properties, trophic status, and geographical locations in open ocean waters, estuaries, and coastal waters. Despite the NOMAD data encompass large samples, only few cruises data (between 2003 and 2007) were considered because satellite sampling for a given station was masked by clouds or affected by sensor digitization problems.

\subsection{Satellite Data}

MODIS-Aqua Level 1A data data were obtained from the US NASA GSFC (Goddard Space Flight Center), and processed using SeaDAS5 to generate Level 2 data (water-leaving radiance $\mathrm{L}_{\mathrm{w}}$ ). Many of these data were collected coincidently with the above field data and few were acquired in highly bloomed waters of the Arabian Sea. For the reason that $\mathrm{L}_{\mathrm{w}}$ data at the short wavelengths are profoundly deteriorated by the SAC algorithm, all Level $2 \mathrm{~L}_{\mathrm{w}}$ data were reprocessed based on the new spectral models and then converted to remote sensing reflectance $\left(\mathrm{R}_{\mathrm{rs}}(\lambda)\right)$ using the standard procedures avail- able with SeaDAS. In theory, the spectral models developed in this study can be applied to the entire global ocean colour dataset. In practice, however, due to large volume of MODIS data, a few coastal and offshore regions were selected to demonstrate their accuracy and reliability.

\section{Spectral Models}

To avoid known problems with atmospheric correction at the short wavelengths (note the inaccuracy of the atmospheric correction grows for decreasing wavelengths so that the $412 \mathrm{~nm}$ waveband is the most affected one [11], a correction is carried out in two steps based on the definition of water into two types: relatively clear waters $\left(\mathrm{Chl}<0.5 \mathrm{mg} / \mathrm{m}^{3}\right)$ and optically complex waters (bloom, plume and coloured waters where $\mathrm{Chl}>0.5 \mathrm{mg} / \mathrm{m}^{3}$ and negative $\mathrm{L}_{\mathrm{w}}$ (412) as produced by the SAC algorithm). Accordingly, two separate sets of spectral models are developed considering the fact that the water-leaving radiance for clear waters is weakly variable with a smooth decrease towards the shorter wavelengths (412 $\mathrm{nm}$ ) with increasing pigment concentration which is in contrast with that for optically complex waters. These models take into account a change (distortion) in spectral shape characteristics in the blue wavelengths (412 and $443 \mathrm{~nm}$ ) for estimating the atmospheric correction distortion and reconstructing the $\mathrm{L}_{\mathrm{w}}$ spectra in the visible domain (412 - $555 \mathrm{~nm})$. For optically complex waters (Chl $>0.5 \mathrm{mg} / \mathrm{m}^{3}$; negative $\left.\mathrm{L}_{\mathrm{w}}(412)\right)$, the spectral models rely on the normalized spectral difference between $\mathrm{L}_{\mathrm{w}}$ (412) and $L_{w}$ (443) multiplied by its wavelength ratio factor which is then added with measurements at each wavelength, as shown in Equation (1), where $\lambda_{1}=412$, $\lambda_{2}=443$ and $\kappa=0.85$. To compensate for a maximum distortion at $412 \mathrm{~nm}$ and ensure spectral continuity, the normalized spectral values (sum) of $\mathrm{L}_{\mathrm{w}}$ (412) and $\mathrm{L}_{\mathrm{w}}$ (443) and coefficient $\kappa$ are used in the above equations. These models ensure a maximal shift in $\mathrm{L}_{\mathrm{w}}$ (toward positive) when its distortion is elevated and a minimal shift in $\mathrm{L}_{\mathrm{w}}$ when it is undistorted.

$$
\left.\begin{array}{l}
\left.n_{-} L_{w}(412)=\left[\left(\left(L_{w}(412)+L_{w}(443)\right) / 2\right)+\left(\left(L_{w}(443)-L_{w}(412)\right) / 2\right)\right] \times\left[\lambda_{1} / \lambda_{2}\right] \times \kappa\right) \\
n_{-} L_{w}(443)=\left[\left(L_{w}(443)\right)+\left(\left(L_{w}(443)-L_{w}(412)\right) / 2\right)\right] \times\left[\lambda_{1} / \lambda_{2}\right] \\
n_{-} L_{w}(488)=\left[\left(L_{w}(488)\right)+\left(\left(L_{w}(443)-L_{w}(412)\right) / 2\right)\right] \times\left[\lambda_{1} / \lambda_{2}\right] \\
n_{-} L_{w}(531)=\left[\left(L_{w}(531)\right)+\left(\left(L_{w}(443)-L_{w}(412)\right) / 2\right)\right] \times\left[\lambda_{1} / \lambda_{2}\right] \\
n_{-} L_{w}(551)=\left[\left(L_{w}(551)\right)+\left(\left(L_{w}(443)-L_{w}(412)\right) / 2\right)\right] \times\left[\lambda_{1} / \lambda_{2}\right]
\end{array}\right\}
$$




$$
\left.\begin{array}{l}
n L_{w}(412)=L_{w}(412)+[(551-489) /(551-412)] \times\left[(412 / 551)^{2}-\left(L_{w}(551) / L_{w}(489)\right)^{0.5}\right] \\
n L_{w}(443)=L_{w}(443)+[(551-489) /(551-412)] \times\left[(412 / 551)^{2}-\left(L_{w}(551) / L_{w}(489)\right)^{0.5}\right] \\
n L_{w}(489)=L_{w}(489)+[(551-489) /(551-412)] \times\left[(412 / 551)^{2}-\left(L_{w}(551) / L_{w}(489)\right)^{0.5}\right] \\
n L_{w}(531)=L_{w}(531)+[(551-489) /(551-412)] \times\left[(412 / 551)^{2}-\left(L_{w}(551) / L_{w}(489)\right)^{0.5}\right] \\
n \_L_{w}(551)=L_{w}(551)+[(551-489) /(551-412)] \times\left[(412 / 551)^{2}-\left(L_{w}(551) / L_{w}(489)\right)^{0.5}\right]
\end{array}\right\}
$$

For relatively clear waters $\left(\mathrm{Chl}<0.5 \mathrm{mg} / \mathrm{m}^{3}\right)$, a correction is achieved based on a set of spectral models (one for each band) to obtain the best spectral shape of $\mathrm{L}_{\mathrm{w}}$ $(412-551 \mathrm{~nm})$. These models that readjust the spectral shape of the $\mathrm{L}_{\mathrm{w}}$ from the SAC algorithm are defined in Equation (2).

The newly derived water-leaving radiance values will be helpful to reduce errors in bio-geochemical products such as chlorophyll concentration in optically complex waters (Figure 1). For example, the OC3 algorithm [12] estimates $\mathrm{Chl}$ a from a cubic polynomial formulation by using the maximum band ratio determined as the greater of the $R_{r s}(443) / R_{r s}(551)$ or $R_{r s}(488) / R_{r s}(551)$. It is then feasible to obtain error in the atmospheric correction and in the retrievals of pigment concentrations in both clear and optically complex waters.

\section{Results}

The comparison between original (SAC) and reconstructed $R_{r s}$ (spectral models) is shown in Figure 2 for

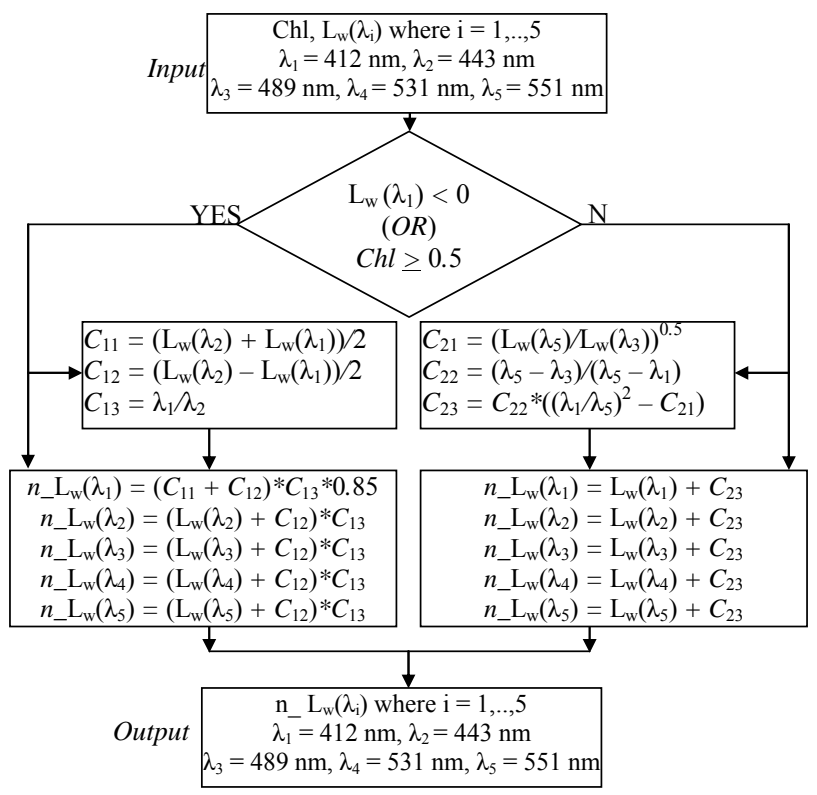

Figure 1. Flowchart showing an iterative method to reconstruct the atmospherically distorted spectra. $n_{-} \mathbf{L w}$ is the reconstructed (new) water-leaving radiance. bloomed and turbid waters in the Arabian Sea, using several MODIS-Aqua data collected during the year 2007. It reveals dramatic anomalous differences between these two spectra, i.e., $R_{r s}$ produced by the SAC algorithm are significantly biased low and negative at short wavelengths (412 and $443 \mathrm{~nm}$ ) and this resulted in a large distortion of the radiance structures across the visible spectrum (left). In particular, most of the distorted spectra were observed in bloomed waters. The effect of the spectral models on raising radiance values particularly at 412 and 443 is clearly seen in Figure 2 (right). The physically realistic shape of $R_{r s}(\lambda)$ is also typical for waters with phytoplankton blooms in the Arabian Sea [13].

Because the quality of the atmospheric correction affects the quality of the $R_{r s}(\lambda)$ which is key to the estimation of pigments and other geophysical products, satellite-derived remote sensing reflectances were compared with those from the in-situ measurements in both clear and optically complex waters. Figure 3 shows comparisons between the original (SAC) $R_{r s}(\lambda)$ and reconstructed $R_{r s}(\lambda)$ and in-situ $R_{r s}(\lambda)$ at the selected five wavelengths. Although there is no remarkable difference, the results in these plots show a reasonably good matchup between reconstructed and in-situ reflectance measurements. Most of the corrected $R_{r s}(\lambda)$ values are aligned closer to the $1: 1$ line as compared with those from the SAC algorithm. To gain further insight into the differences between the satellite $R_{r s}(\lambda)$ and in-situ $R_{r s}(\lambda)$, the mean relative error (MRE), root means square error (RMSE), slope (S), intercept $(\mathrm{I})$, correlation coefficient $\left(\mathrm{R}^{2}\right)$ and bias were calculated using the standard statistical procedures and the results are summarized in Tables 1(a) and (b). Notably, these statistics are better for the reconstructed $R_{r s}(\lambda)$ than for the SAC algorithm (see relatively lower MRE, RMSE and I, higher $\mathrm{S}$ and $\mathrm{R}^{2}$, and almost same biases). This clearly indicates significant improvements over the SAC algorithm.

The effect of atmospheric correction errors on pigment retrievals was also assessed using the OC3 algorithm as applied to both the original $R_{r s}(\lambda)$ and reconstructed $R_{r s}(\lambda)$ (Figures 4(a) and (b)). As noted earlier, the uncorrected $R_{r s}(\lambda)$ showed noticeable overestimations in Chl with 

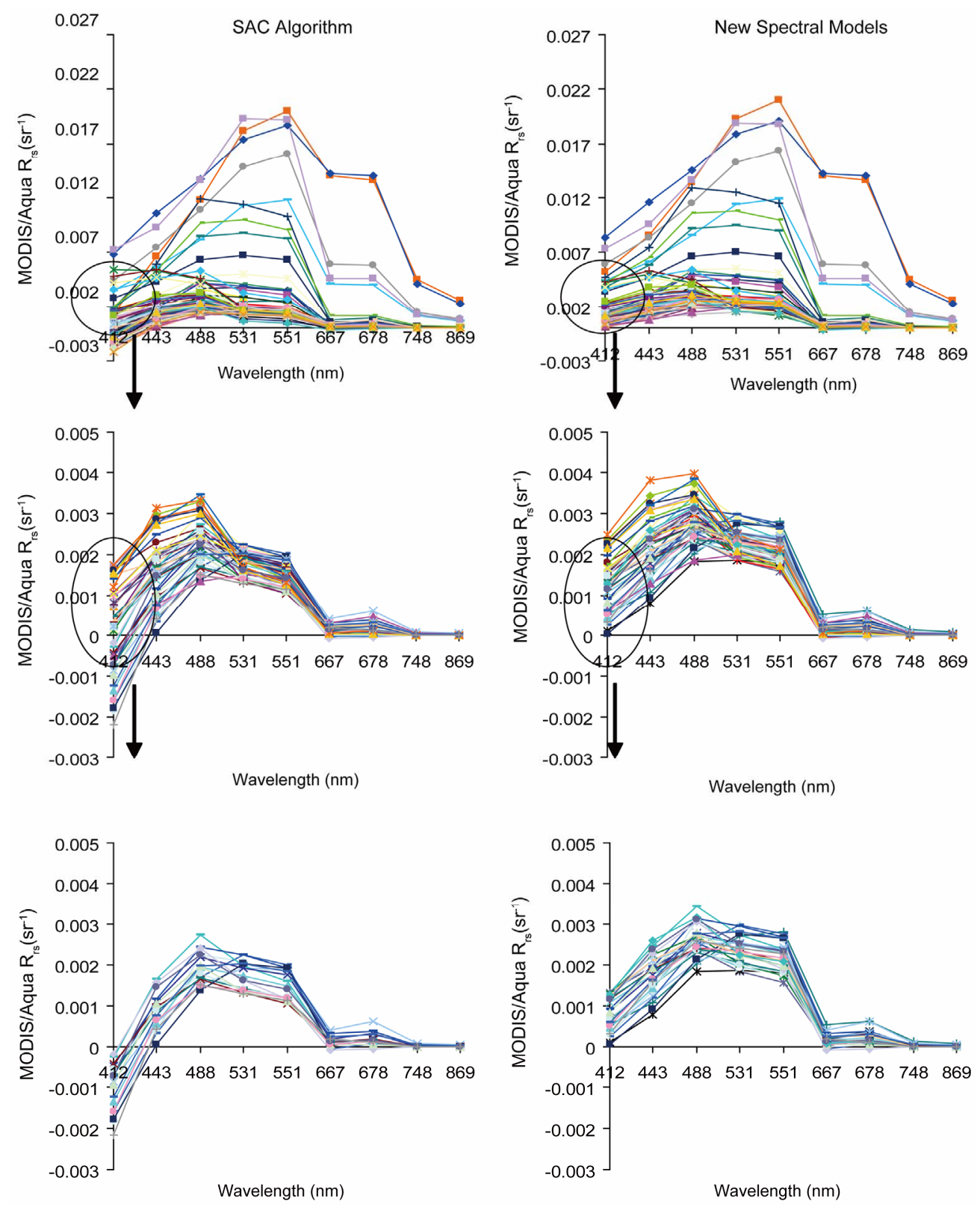

Figure 2. Examples of the remote sensing reflectance $\left(R_{r s}\right)$ spectra obtained from several MODIS-Aqua data using the SAC algorithm (left) and the spectral models (right). MODIS-Aqua data from bloomed and coastal waters in the Arabian Sea are: A2007006065500, A2007007073500, A2007008064500, A2007009073000, A2007017095500, A2007018072000, A2007021075000, A2007022065500, A2007023074000, A2007024064500, A2007025073000, A2007026063500, A2007028075500, and A2007029070500.

respect to in situ measurements in bloomed/coastal waters [13], although producing $\mathrm{Chl}$ consistent with the in-situ data in clear waters.

By contrast, the validation matchups between in-situ Chl and satellite Chl from the reconstructed $R_{r s}(\lambda)$ are very excellent and demonstrate good agreement in both clear and optically complex waters (lower MRE, RMSE, $\mathrm{I}$ and bias, and higher $\mathrm{S}$ and $\mathrm{R}^{2}$ ). The averaged minimum, mean and maximum $\mathrm{Chl}$ values for this case are also in good agreement with in-situ data (Table 1(b)), with its mean value being 1.65 times lower than that produced by the former case.

Shown in Figures 4(c) and (d) are two hypothetical cases from the bloom water (c) and clear water (d). It should be noted that when $\mathrm{Chl}>5 \mathrm{mg} / \mathrm{m}^{3}$, the situation is even worse (also see Figure 4(b)) and an excessive overcorrection is often inevitable with the SAC algorithm because of its excessive aerosol correction. This overcorrection or reduction in $\mathrm{L}_{\mathrm{w}}$ eventually appears as an elevated pigment concentrations as observed in Figures 

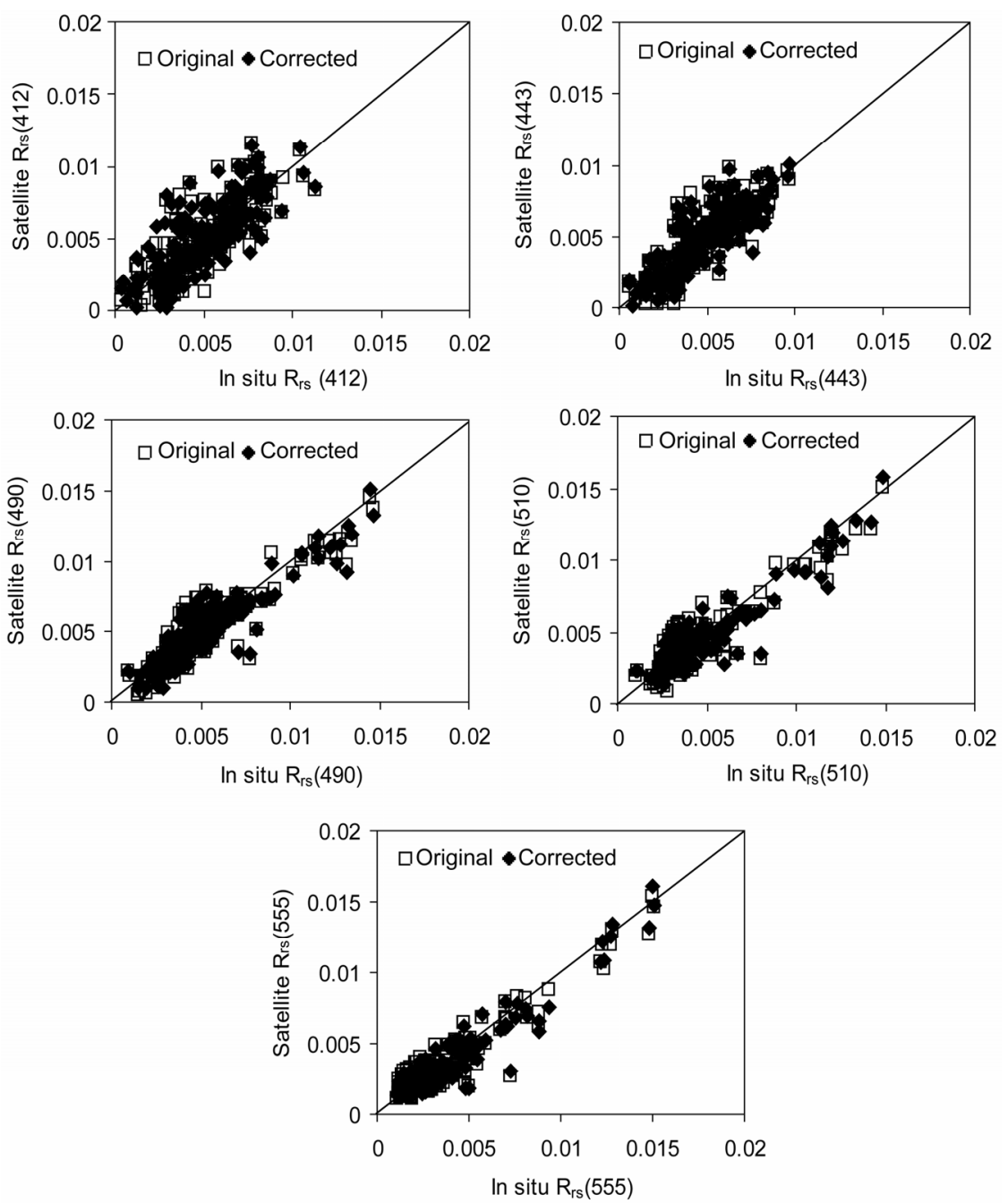

Figure 3. MODIS-derived remote sensing reflectance $\left(R_{r s}\right.$ in $\left.s r^{-1}\right)$ values compared with in-situ measurements for the wavelengths of 412, 443, 490, 510 and $555 \mathrm{~nm}$. The in-situ data collected in both clear and optically complex waters were obtained from the NOMAD database.

4(a) and (b). On the contrary, the spectral models have potential to not only improve $\mathrm{L}_{\mathrm{w}}$ retrievals (thus constituents' concentrations) in optically complex waters but also reliably reproduce these spectra in clear waters.

Optically complex waters are consistently turbid due to the presence of suspended sediments and algal blooms and have large NIR water-leaving radiances. The enhanced water signal interferes with the SAC algorithm to produce unacceptable errors in retrieved water-leaving radiance and pigment concentrations. This leaves only two chaises for users who need to derive variables such as seasonal mean concentrations or annual primary production: either (1) to completely discord the spectrally distorted $\mathrm{L}_{\mathrm{w}}$ data or (2) to use them as is, in error. In either case the results will be biased. Our spectral models reduce errors in estimated water-leaving radiance for both optically complex and clear waters. The number of negative water-leaving radiance pixels drops signifi- cantly. Furthermore, data from many coastal areas with quality masks due to atmospheric correction failure can be recovered. Consequently, the spatial patterns in the masked areas, even if the accuracy in the estimated waterleaving radiance or pigment concentrations is doubtful, can be derived. The improvement in the water-leaving radiance data will be helpful to improve the accuracy bio-geo-physical products. This scheme is easy to use for any operational processing of the satellite ocean colour data on daily basis.

\section{Conclusion}

In conclusion, the new models show promise in reconstructing the spectrally distorted water-leaving radiance in both clear and optically complex waters. The spectral shape/form produced by these models is found to be better consistent with in-situ measurements in the visible 
Table 1. (a) and (b) Comparison of algorithm performances using in-situ data sets (e.g., remote sensing reflectance $R_{r s}\left(s^{-1}\right)$ and Chlorophyll concentration $\left(\mathbf{m g} / \mathbf{m}^{3}\right)$ ).

(a)

\begin{tabular}{ccccccc}
\hline & MRE & RMSE & Slope & $\mathbf{R}^{2}$ & Bias & Sample density \\
\hline$R_{r s}(412)$ & 0.0298 & 0.1846 & 0.5017 & 0.5882 & 0.0700 & 194 \\
$R_{r s}(443)$ & 0.0111 & 0.1836 & 0.5636 & 0.5628 & 0.0261 & 194 \\
$R_{r s}(490)$ & 0.0041 & 0.1067 & 0.7947 & 0.7214 & 0.0096 & 194 \\
$R_{r s}(510)$ & 0.0084 & 0.1105 & 0.8246 & 0.6890 & 0.0202 & 194 \\
$R_{r s}(555)$ & 0.0027 & 0.1231 & 0.9457 & 0.7818 & 0.0069 & 194 \\
& & & & & 194 \\
$R_{r s}(412)$ & 0.0098 & 0.2196 & 0.5747 & 0.4735 & 0.0230 & 194 \\
$R_{r s}(443)$ & 0.0076 & 0.1553 & 0.6582 & 0.6045 & 0.0177 & 194 \\
$R_{r s}(490)$ & 0.0043 & 0.1021 & 0.8309 & 0.7321 & 0.0099 & 194 \\
$R_{r s}(510)$ & 0.0085 & 0.1064 & 0.8601 & 0.7011 & 0.0214 & 194 \\
$R_{r s}(555)$ & 0.0022 & 0.1186 & 0.9800 & 0.7957 & 0.0074 & 194 \\
& & & Chlorophyll & & -0.043 & \\
Old & -0.123 & 0.2096 & 0.8308 & 0.8590 & 0.041 & \\
New & -0.124 & 0.1900 & 0.8655 & 0.8769 & & 194 \\
\hline
\end{tabular}

(b)

\begin{tabular}{cccc}
\hline & In-situ & OC3-Chl from SeaDAS $\boldsymbol{R}_{r s}$ & OC3-Chl from corrected $\boldsymbol{R}_{r s}$ \\
\hline Minimum & 0.076 & 0.0602 & 0.079 \\
Maximum & 10.62 & 32.037 & 19.39 \\
Mean & 0.958107 & 1.405 & 1.225 \\
\hline
\end{tabular}

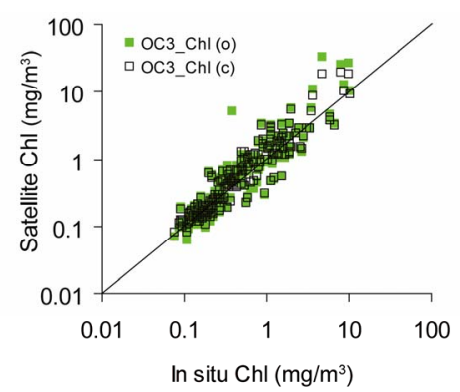

(a)

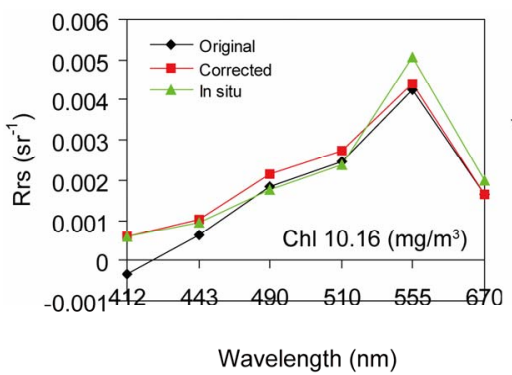

(c)

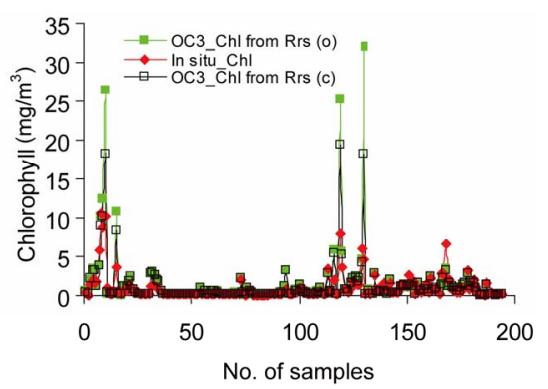

(b)

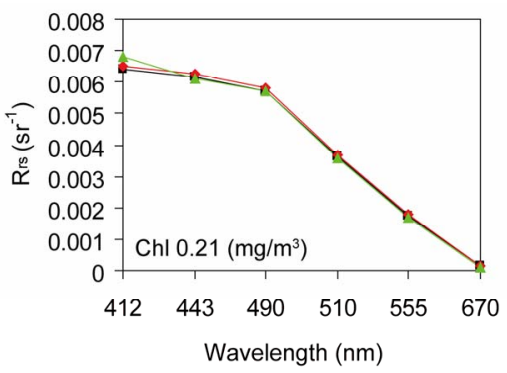

(d)

Figure 4. Scatterplot illustrating the comparison of estimated Chl concentrations by OC3 algorithm (using original $R_{r s}(\lambda)$ from the SAC algorithm and reconstructed $R_{r s}(\lambda)$ ) to in-situ Chl concentrations (a), Chlorophyll at different stations obtained from the in-situ measurements and estimated from the OC3 algorithm by using the original and reconstructed $R_{r s}(\lambda)$, (c) and (d) $R_{r s}$ spectra for two typical cases-Algal bloom (c) and clear waters (b). 
domain (412 - $555 \mathrm{~nm}$ ) that allows more accurate estimations of constituents' concentrations. The minimal errors of the satellite validation matchups imply that these spectral models can be used to improve the various biogeophysical products desired for coastal oceanic waters. Though the spectral models have been described for MODIS/SeaWiFS imagery, it can be applied rather generally to other satellite-based and probably also airborne ocean colour sensors (with only two near-infrared bands (i.e., 765 and $865 \mathrm{~nm}$ ) and no shortwave bands). The directions for further research include a more detailed validation of these models with large in-situ data sets from highly turbid and productive waters, and an attempt to tune it to have a wider applicability. The effect of absorbing aerosols on the retrieved water-leaving radiance will be assessed and further refinements of the models will be anticipated.

\section{Acknowledgements}

This work was supported by the ISRO-IITM cell project (ICSR/ISRO-IITMJPC34/2009). The author gratefully acknowledges the NASA Ocean Biology Processing Group for making available the global, high quality in situ bio-optical (NOMAD) dataset as well as the global coverage MODIS-Aqua data to this study.

\section{REFERENCES}

[1] H. R. Gordon, “Atmospheric Correction of Ocean Colour Imagery in the Earth Observing System Era," Journal of Geophysical Research, Vol. 102, No. D14, 1997, pp. 17081-17106. doi:10.1029/96JD02443

[2] H. R. Gordon and M. Wang, "Retrieval of Water-Leaving Radiance, Aerosol Optical Thickness over the Oceans with SeaWiFS: A Preliminary Algorithm," Applied Optics, Vol. 33, No. 3, 1994, pp. 443-452. doi:10.1364/AO.33.000443

[3] S. W. Bailey, B. A. Franz and P. J. Werdell, "Updated NIR Water Leaving Radiance Estimation for Ocean Colour Data Processing," Optics Express, Vol. 18, No. 7, 2010, pp. 7521-7527. doi:10.1364/OE.18.007521

[4] C. Moulin, H. R. Gordon, V. F. Banzon and R. H. Evans, "Assessment of Saharan Dust Absorption in the Visible from SeaWiFS Imagery," Journal of Geophysical Research: Atmospheres, Vol. 106, No. D16, 2001, pp. 18239-18249. doi:10.1029/2000JD900812

[5] K. G. Ruddick, F. Ovidio and M. Rijkeboer, "Atmospheric Correction of SeaWiFS Imagery for Turbid Coastal and Inland Waters," Applied Optics, Vol. 39, No. 6, 2000, pp. 897-913. doi:10.1364/AO.39.000897

[6] R. A. Arnone, P. Martinolich, R. W. Gould, R. Stumpf and S. Ladner, "Coastal Optical Properties Using SeaWiFS," Proceedings of Ocean Optics XIV Conference, Kailua-Kona, Washington DC, 10-13 November 1998, pp. 10-13.

[7] D. A. Siegel, G. M. Wang, S. Maritorena and W. Robinson, "Atmospheric Correction of Satellite Ocean Colour Imagery: The Black Pixel Assumption," Applied Optics, Vol. 39, No. 21, 2000, pp. 3582-3591. doi:10.1364/AO.39.003582

[8] C. Hu, K. L. Carder and F. E. Muller-Karger, "Atmospheric Correction of SeaWiFS Imagery over Turbid Waters: A Practical Approach," Remote Sensing of Environment, Vol. 74, No. 2, 2000, pp. 195-206. doi:10.1016/S0034-4257(00)00080-8

[9] P. J. Werdell and S. W. Bailey, “An Improved In-Situ Bio-Optical Data Set for Ocean Colour Algorithm Development, Satellite Data Product Validation," Remote Sensing of Environment, Vol. 98, No. 1, 2005, pp. 122140. doi:10.1016/j.rse.2005.07.001

[10] A. Morel and B. Gentili, "A Simple Band Ratio Technique to Quantify the Coloured: Dissolved and Detrital Organic Material from Ocean Colour Remotely Sensed Data," Remote Sensing of Environment, Vol. 113, No. 5, 2009, pp. 998-1011. doi:10.1016/j.rse.2009.01.008

[11] J. E. O'Reilly, S. Maritorena, B. G. Mitchell, D. A. Siegel Kendall, L. Carder, S. A. Garver, M. Kahru and C. McClain, "Ocean Colour Chlorophyll Algorithms for SeaWiFS," Journal of Geophysical Research: Ocean, Vol. 103, No. C11, 1998, pp. 24937-24953.

[12] P. Shanmugam, "A New Bio-Optical Algorithm for the Remote Sensing of Algal Blooms in Complex Ocean Waters," Journal of Geophysical Research, Vol. 116, No. C4, 2001, Article ID: C04016. doi:10.1029/2010JC006796

[13] Z. P. Lee, "Remote Sensing of Inherent Optical Properties: Fundamentals, Tests of Algorithms and Applications," International Ocean-Colour Coordinating Group, Dartmouth, 2006. 